\title{
Diversidad y patrimonio en los museos
}

\author{
Mauricio Lorca | doctor en gestión de la cultura y el patrimonio
}

URL de la contribución <www.iaph.es/revistaph/index.php/revistaph/article/view/3878>

En las últimas décadas los museos han reformulado sus acciones y misiones para intentar contribuir a la memoria colectiva y reforzar los sentimientos de pertenencia e identidad mediante la representación dinámica de las comunidades en las que se insertan. Así, paulatinamente, han dejado de ser entendidos como meros lugares de conservación y exhibición de objetos para ser vistos como entidades al servicio del ser humano y la sociedad.

Vale decir que los museos han asumido el desafío de actualizar sus contenidos para representar a sociedades cada vez más heterogéneas y que reivindican su diversidad. En otras palabras, los museos se están convirtiendo en instituciones que ya no aspiran a representar las identidades de forma unitaria sino, más bien, como un crisol de culturas e identidades en permanente diálogo y transformación.

En efecto, el desplazamiento conceptual y la extensión que ha experimentado el campo patrimonial durante las últimas décadas como resultado de la diversificación de actores que pueden activarlo, han llegado a convertirlo, según Ariño (2012), en un verdadero movimiento cívico. De ahí que el patrimonio deba ser entendido no tanto como un valor en sí mismo sino como el resultado de un proceso de producción. Esto si se asume que para que cualquier elemento sea considerado patrimonio debe sortear una dinámica de producción conocida como patrimonialización, entendida como la articulación de un discurso mediante la identificación, la selección, el ordenamiento, el estudio, la interpretación, la certificación científica y la exhibición de un bien cultural (DAVALLON, 2006; FRANÇOIS; HIRCZAK; SENIL, 2006).

De esta forma, las activaciones patrimoniales han dejado de ser de exclusivo interés y responsabilidad pública, pasando también a formar parte del repertorio de accio- nes que emergen y son impulsadas por la sociedad civil o por agentes privados. Esto confirma que parte importante de las dinámicas de patrimonialización contemporáneas representan la democratización de la producción y gestión patrimonial. Así, en la medida que las comunidades - 0 , al menos, su porción organizada - se implican en procesos de ese tipo, aparecen entre los sujetos sociales involucrados modelos de entendimiento que alientan su vinculación, comunicación y coordinación en pos de la solución de desafíos comunes.

Los museos han comenzado a rebatir antiguas concepciones que han sido sinónimo de la sacralización de muchos objetos de acuerdo a criterios de materialidad, antigüedad y/o cualidades estéticas, para incorporar bienes culturales cuya significancia remite a la memoria, las prácticas sociales y la vida cotidiana de los grupos representados. De esta manera, han surgido paradigmas museológicos que buscan adaptarse a las necesidades de sociedades cada vez más amplias y diversas con el fin de revertir la exclusión de actores sociales que han permanecido ausentes en sus discursos y sus espacios expositivos, promoviendo su participación como motor de las museografías, incluyéndolos en ocasiones a la gestión del patrimonio que custodian con el objetivo de que sus productos sea el resultado de un trabajo compartido y dinámico. Esto significa el reforzamiento de la identificación, la apropiación y la participación de los grupos respecto el reconocimiento y la exposición de los bienes culturales que los representan de forma compartida.

La construcción de repertorios patrimoniales compartidos emerge entonces como un soporte estratégico para la construcción y el reconocimiento de identidades variadas y dinámicas que alientan su reconocimiento y proyección en el tiempo. Así, los museos se constituyen hoy en instituciones que aportan nuevas visiones sobre 


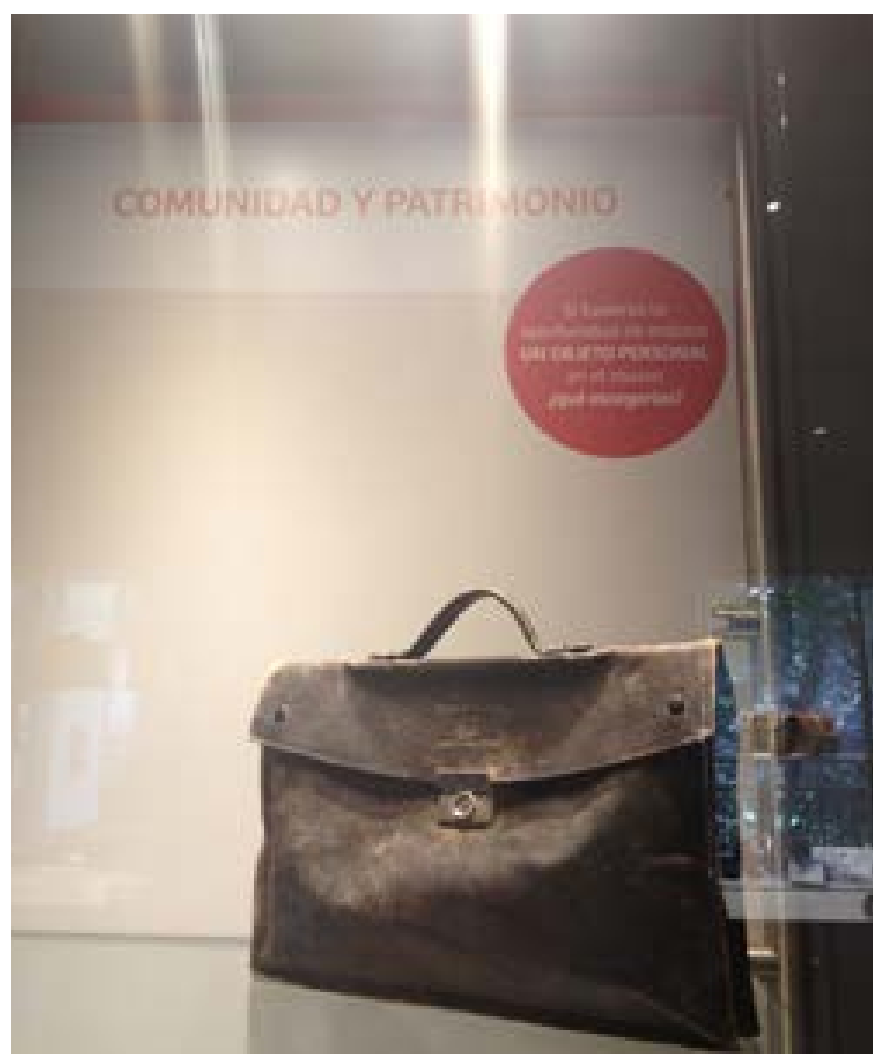

Bolso de escuela, parte de la exhibición del Museo de la Educación Gabriela Mistral, Santiago de Chile | foto Fotografía de Andrea Torres

las sociedades, cuestionando la relación que tienen con los objetos que resguardan y redefiniendo los elementos simbólicos que añaden a sus colecciones y exponen (HAINARD, 2007; ALCALDE; BOYA; ROIGÉ, 2010). Para, de forma concomitante, integrar nuevas estrategias de presentación y representación de las sociedades modernas mediante la identificación y la incorporación de distintos discursos identitarios y, consiguientemente, de elementos novedosos con la capacidad de representar las sociedades de interés.

Es decir, actualmente los museos buscan desarrollar guiones permanentes o temporales que, fundados en una mirada museológica crítica o rupturista, desarrollan exposiciones fuertemente provocadoras y reflexivas del entorno contemporáneo. Dentro de las cuales los objetos adoptan un papel secundario pues no son expues- tos por el valor que tienen en sí mismos, sino por los múltiples sentidos que les han conferido los sujetos y sus comunidades, reelaborando también el valor de lo patrimonial.

\section{BIBLIOGRAFÍA}

- AlCALDE, G.; BOYA J.; ROIGÉ, X. (ed.) (2010) Museus d'avui. Els nous museus de societat. Girona: Institut Català de Recerca en Patrimoni Cultural, 2010

- ARIÑo, A. (2012) La patrimonialización de la cultura y sus paradojas postmodernas. En LISÓN, C. (dir.) Antropología: Horizontes patrimoniales. Valencia: Tirant Humanidades, 2012, pp. 208-229

- DAVALLON, J. (2006) Le don du patrimoine: Une approche communicationnelle de la patrimonialisation. Paris: Hermès Sciences-Lavoisier, 2006

- FRANÇOIS, H.; HIRCZAK, M.; SENIL, N. (2006) Territoire et patrimoine: La co-construction d'une dynamique et de ses ressources. Revue d'économie régionale et urbaine 5, 2006, pp. $683-700$

- HAINARD, J. (2007) L'expologie bien tempérée. Quaderns-e de l'Institut Català d'Antropologia 9, 2007 <http://www.raco. cat/index.php/QuadernseICA/article/view/73512/131223> [Consulta: 22/01/2017] 